\title{
Histological Observations on a Muscle Mass from a Large Marine Mammal Struck by a Jetfoil in the Sea of Japan
}

\author{
Yoshiharu Honma, ${ }^{* 1}$ Akira Chiba, ${ }^{* 2}$ and Tatsuo Ushiki ${ }^{* 1}$ \\ ${ }^{*}$ Department of Anatomy, Niigata University School of Medicine, Asahi, Niigata 951, Japan \\ ${ }^{*}$ School of Dentistry at Niigata, Nippon Dental University, Hamaura, Niigata 951, Japan
}

(Received November 22, 1996)

\begin{abstract}
A histological study was made to determine the identity of the animal which was struck by a jetfoil (rapid-transit boat) operating for the Sado Line in the Sea of Japan, on 31 October, 1994. The material examined, a hairless mass of red and white muscle, $193 \mathrm{~g}$ in weight, was found in the left intake pipe of the boat. Histological examination revealed pieces of bone, comprising compact and spongy components, between the muscle fibers and tendon. The bone, lamellar in nature, included many cavities containing osteocytes. A single type of muscle spindle, comprising 9 intrafusal fibers, in association with myelinated nerve bundles, was observed. These indicated that the animal struck by the jetfoil was a cetacean.
\end{abstract}

Key words: cetacean collision, cetacean muscle, jetfoil, lamellar bone, muscle spindle

Records of large marine animals, including cetaceans, pinnipeds, marine turtles and snakes, ribbon fishes, great sharks and giant squids, stranded on the coast of Nigata and Sado Island in the Sea of Japan have been reviewed in detail. ${ }^{1,2)}$ A mass stranding of Pacific white-sided dolphins, Lagenorhynchus obliquidens, during severe winter conditions was also reported. ${ }^{3)}$ However, histological studies on the internal organs of cetaceans stranded on the coast of Niigata District are few, being limited to three cases conducted in order to determine whether or not breeding occurred in the Sea of Japan. ${ }^{4-6)}$

The jetfoil, a rapid-transit hydrofoil, entered operation in Japanese waters on the Sado Line in May, 1977. The boat, developed by the Bocing Company, U.S.A., has subsequently maintained a schedule between the West Port of Niigata, the largest city on the west coast of the main island of Japan (Honshu), and Ryotsu Port, Sado Island, in the Sea of Japan. Five cases of collisions with undetermined objects have occurred since the beginning of the service $^{7}$ (Fig. 1). Although evidence has been circumstantial, it is likely that the animals struck each have been cetaceans.

The five collisions are detailed in Table 1. The last instance, on 25 November, 1995, was especially noteworthy due to the injuries suffered by 13 passengers. In addition, damage to the boat was considerable: the bow hydrofoil was broken off and lost (sea depth $120 \mathrm{~m}$ ).

To avoid further collisions with (in particular) cetaceans, the Sado Line Company has adopted acoustic equipment with an evasive-sound producer, which has been tested on sperm whale populations near the Spanish Canary Islands, in the Atlantic Ocean.

In an incident on 31 October, 1994, damage to the boat was the least (Table 1), with a small mass of muscle from the struck animal being lodged in the left suction pipe, located near the stern. This material was offered for examination in order to determine the identity of the animals.

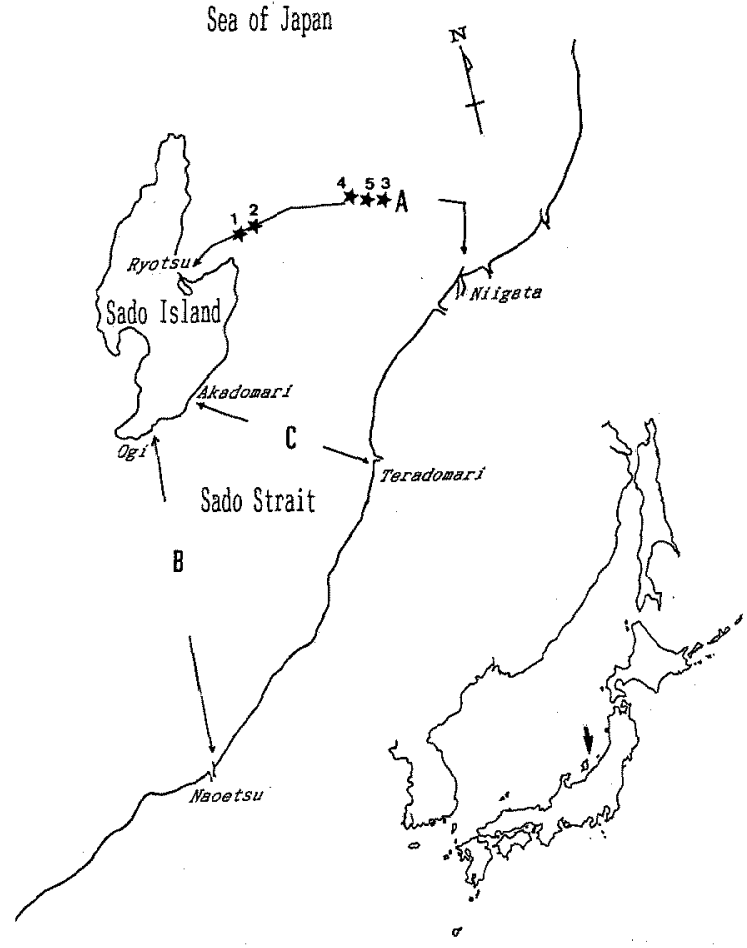

Fig. 1. Map of Sado Strait and the regular Sado Line routes, showing the points of collision of the jetfoil with undetermined objects, probably cetaceans (for $1-5$, see Table 1 ).

A: Niigata-Ryotsu route, B: Naoetsu-Ogi route, C: TeradomariAkadomari route.

\section{Materials and Methods}

The frozen muscle mass, $193 \mathrm{~g}$ in weight and comprising red and white parts (Fig. 2A), was thawed gently and im- 

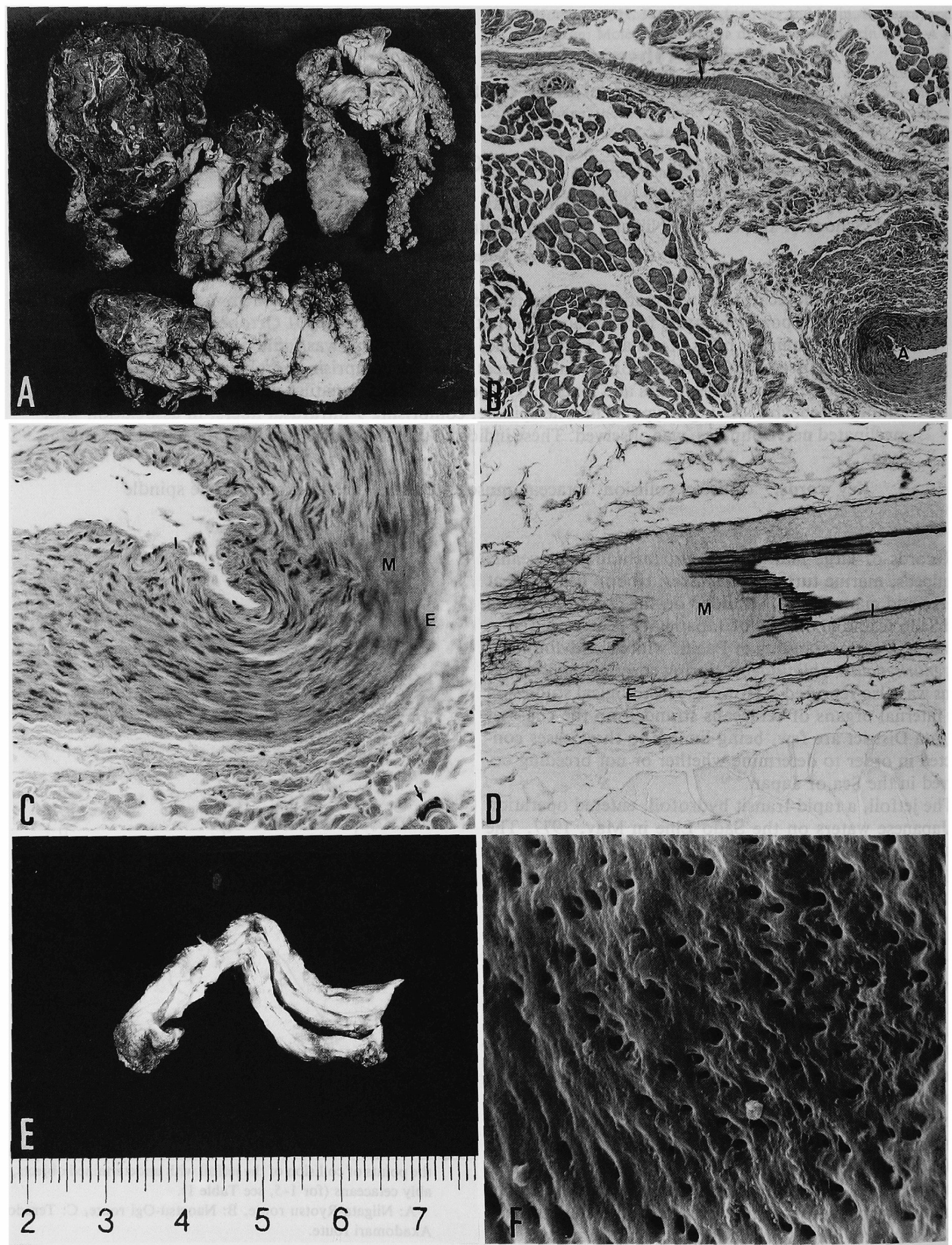

Fig. 2. Microscopy and macroscopy from a large marine mammal struck by a jetfoil.

A: Muscle masses from an unidentified animal, probably a cetacean. Note that the masses include both lean and adipose portions. $(\times 1 / 2)$ B: Light microscopy of cross-section of muscule mass, showing numerous muscle fibers and a thick-walled muscular artery (A). Hematoxylin-eosin stain (HE). ( $\times 42)$ C: Enlarged view of cross-section of artery. A thin intima (I), thick tunica media (smooth muscle) (M) and tunica externa (E) can be distinguished. Macrophages (arrow) characterized by the melanin-like granules occur sporadically between the muscle fibers. HE stain. ( $\times 210)$ D: Light microscopy of longitudinal section of artery. Tunica intima (I) lined with an internal elastic lamina (L), tunica media and tunica externa $(\mathrm{E})$ are distinguishable. Aldehyde-fuchsin (AF) stain. ( $\times 210)$ E: Macroscopy of thick and dense collagenous bundles (tendon), interven- 

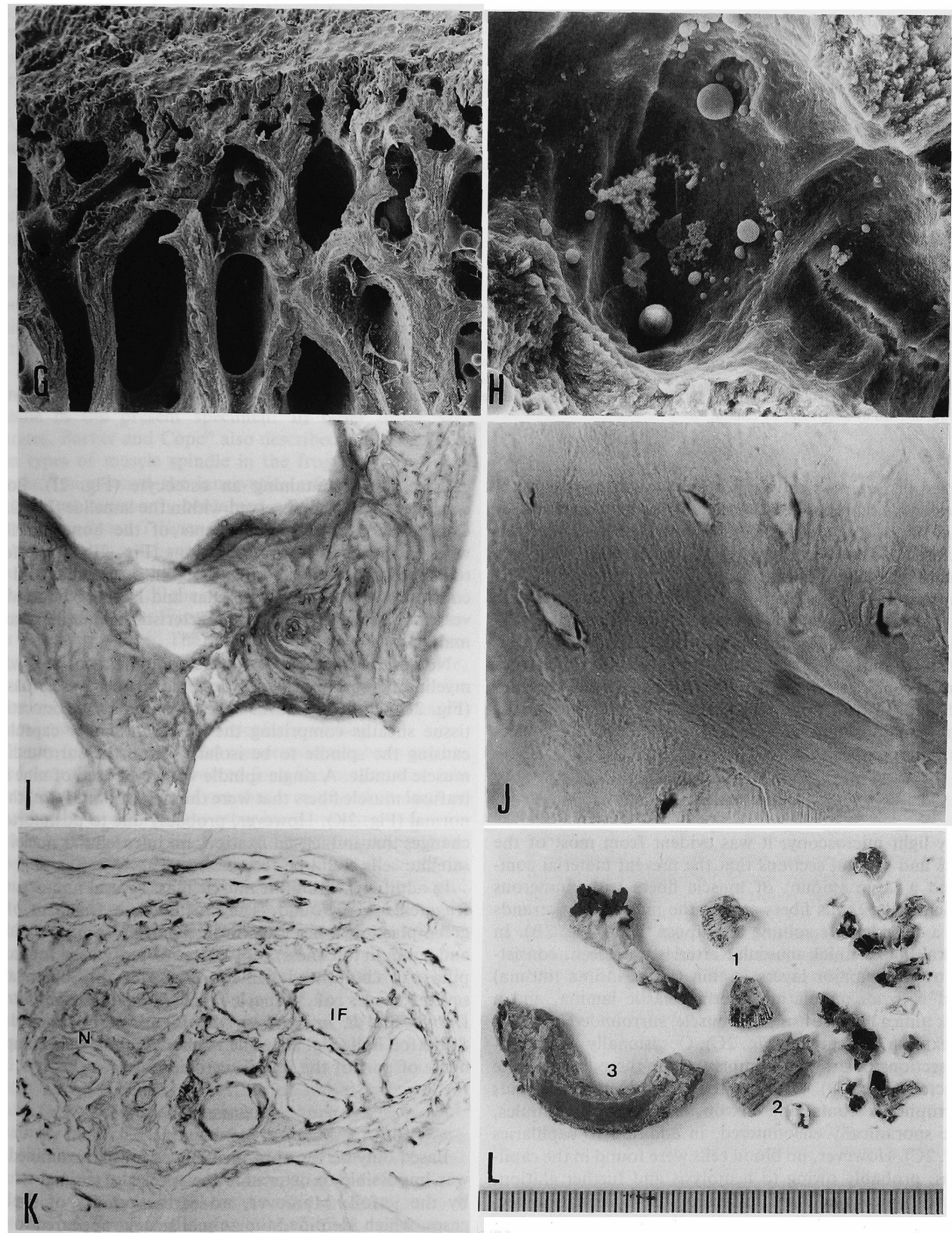

ing in the muscle masses. (cm) F: SEM image of spongy bone fragment showing the surface structure. $(\times 1200)$ G: SEM image of trabecula interior wall. $(\times 40) \mathrm{H}$ : SEM image of trabecula interior wall. Note several fat droplets. $(\times 3900)$ I: Light microscopy of bone fragment, showing lamellar structure. HE stain. $(\times 100) \mathrm{J}$ : Light microscopy of bone fragment, showing cavities with osteocytes. HE stain. $(\times 1500) \mathrm{K}:$ Light microscopy of a muscle spindle consisting of intrafusal fibers (IF) associated with nerve bundles (N). AF stain. $(\times 400)$ L: Fragments of barnacle shells (Balanus spp.) formerly attached to the jetfoil (1), putty stopping the gap of a bolt head (2) and a plastic washer (3), which had become embedded in the muscle mass. (mm) 
Table 1. Incidences of Sado Line jetfoil collisions with undetermined objects on the Sea of Japan, since 1974

\begin{tabular}{|c|c|c|c|c|}
\hline Date & $\begin{array}{l}\text { Port of departure } \\
\& \text { ship's name }\end{array}$ & $\begin{array}{l}\text { Time of } \\
\text { collision }\end{array}$ & Location & Remarks \\
\hline 1. 17 Sept., 1978 & $\begin{array}{l}\text { West Niigata } \\
\text { Okesa }\end{array}$ & $7: 00$ & $\begin{array}{c}8 \text { miles off } \\
\text { Himezaki cape, } \\
\text { Sado Isl. }\end{array}$ & $* 1$ \\
\hline 2. 4 Jan., 1985 & $\begin{array}{c}\text { Ryotsu } \\
\text { Mikado }\end{array}$ & $?$ & $\begin{array}{l}\text { Off Suizu, } \\
\text { Sado Isl. }\end{array}$ & $* 2$ \\
\hline 3. 9 Sept., 1992 & $\begin{array}{c}\text { West Niigata } \\
\text { Tsubasa }\end{array}$ & $16: 30$ & $\begin{array}{c}22 \mathrm{~km} \text { off } \\
\text { West Niigata }\end{array}$ & *3 \\
\hline 4. 31 Oct., 1994 & $\begin{array}{c}\text { West Niigata } \\
\text { Suisei }\end{array}$ & $?$ & $\begin{array}{c}25 \mathrm{~km} \text { off } \\
\text { West Niigata }\end{array}$ & $*_{4}$ \\
\hline 5. 25 Nov., 1995 & $\begin{array}{c}\text { West Niigata } \\
\text { Suisei }\end{array}$ & $11: 30$ & $\begin{array}{c}22 \mathrm{~km} \text { off } \\
\text { West Niigata }\end{array}$ & $*_{5}$ \\
\hline
\end{tabular}

*1 2 muscle masses, found, $1 \mathrm{~kg}$ wt. each, including hyaline cartilage.

*2 On 9 Jan., a bruised Globicephala sp., ca. $4 \mathrm{~m}$ in length, was trapped in a gill net installed off Noura, $18 \mathrm{~km}$ south of Suizi.

* Several passengers injured. Seveal masses of pinkish muscle and adipose tissue subsequently seen on the surface. Bow hydrofoil damaged slightly.

$*_{4}$ Subject of present report. A muscle mass, $193 \mathrm{~g}$ in wt., lodged in the intake pipe. Left stern rectifier plate damaged slightly.

*s 13 passengers injured. Bow hydrofoil lost in $120 \mathrm{~m}$ depth. About $150 \mathrm{~m}$ from the above hydrofoil, an object thought to be the posterior half of a relatively large whale was detected by underwater TV camera.

mersed in Bouin's fixative. For light microscopy, several blocks were removed and dehydrated through a graded alcohol series, embedded in paraffin and cut serially at $8 \mu \mathrm{m}$ thickness. The sections were stained with Mayer's hematoxylin-eosin double stain, aldehyde-fuchsin (AF) counterstained with light green-orange $G$, and periodic acid Schiff (PAS) reaction counter stained with light greenorange $\mathrm{G}$, for examination under a light microscope.

For scanning electron microscopy (SEM), tiny pieces from the blocks fixed with $2 \%$ glutaraldehyde were dehydrated, critical point-dried, sputter-coated with platinum-palladium and observed with a Hitachi S-800 electron microscope.

\section{Observations}

By light microscopy, it was evident from most of the cross and sagittal sections that the present material comprised a large amount of muscle fibers with numerous nuclei, collagenous fibers among the muscle fiber strands and a considerable volume of adipose tissue (Fig. 2B). In several places, thick muscular arteries were seen, consisting of three major layers; a thin tunica intima (intima) lined with an undulating internal elastic lamina, and a thick tunica media of smooth muscle, surrounded by a tunica externa (adventitia) (Fig. 2C). Occasionally, longitudinal sections of arteries, comprising the three layers, were detected (Fig. 2D). Between the striated muscle strands macrophages containing brwon, melanin-like granules, were sporadically encountered, in addition to capillaries (Fig. 2C). However, no blood cells were found in the capillaries, probably owing to hemolysis and further elution. Macroscopical and light microscopical examination revealed thick, dense collagenous bundles (tendon) (Fig. 2E). Also found were bone fragments, the surface of which comprised spongy bone in addition to compact bone (Fig. 2F). Complex trabeculae of the spongy bone directed to cavities (Fig. 2G) and fat droplets attached to the interior walls of the trabeculae were observed (Fig, 2H).

Light microscopy, undertaken to disclose the nature of the bone, clearly revealed the lamellae, being numerous cavities, each containing an osteocyte (Fig. 2I). Bone canaliculi were also observed within the lamellae (Fig. 2J), Concentric circular arrangements of the bone lamellae were encountered in some portions (Fig. 2I). These features indicated that the bone tissue in question should be concluded as comprising cellular and lamellar bone with vesselar pathways, which is characteristic of (marine) mammals.

Notably, a single type of muscle spindle associated with myeline nerve bundles was detected in the muscle tissue (Fig. 2K). Both structures were surrounded by connective tissue sheaths comprising the outer and inner capsules, causing the spindle to be isolated from the surrounding muscle bundle. A single spindle was composed of nine intrafusal muscle fibers that were thinner (about $31 \mu \mathrm{m}$ ) than normal (Fig. 2K). However, probably due to postmortem changes that influenced fixation, no intracellular nuclei or satellite cells could be recognized.

In addition, within the muscle mass several non-organic fragments were found. They included; a fragment of a green plastic washer $(20 \mathrm{~mm}$ in diameter, $3 \mathrm{~mm}$ in width and $3 \mathrm{~mm}$ in thickness), tiny pieces of putty used for stopping over a bolt (head diameter $18 \mathrm{~mm}$, length $30 \mathrm{~mm}$ ) and several pieces of barnacle shells (Balanus amphitrite Darwin and $B$. improvisus Darwin) formerly attached to the jetfoil hull (Fig. 2L). The washer and bolt were components of part of the jetfoil rectifier plate.

\section{Discussion}

Based only on the approx. $193 \mathrm{~g}$ of muscle examined, it was impossible to determine the species of animal struck by the jetfoil. Moreover, no earlier reports of similar cases, which identified the animal struck, appeared to exist.

According to the histological criteria, (1) the fact that the bone fragments were diagnosed as cellular excluded bony fish from suspicion, the latter having only noncellular bone. (2) Because the bone was lamellar, reptiles, in particular large marine reptiles, which have nonlamellar bone, could be excluded. (3) Owing to the presence of cavi- 
ties and vesselar pathways in the bone, the possessor was apparently a large marine mammal (reptiles having only loose spongy and nonvesselar bone). In addition, (4) neither hair nor skin equipped with hairs were found, making it likely that the animal involved was not a pinniped.

Accordingly, in spite of the many unknowns, it is likely that the muscle mass was part of the body (=skeletal) muscles of an undetermined species of whale, greater than $4 \mathrm{~m}$ in length and $4 t$ in body weight. In the case of other marine mammals, such as dolphins and porpoises, about $2 \mathrm{~m}$ long and less than $1 \mathrm{t}$, the jetfoil would have easily cleared the animal's body without incident.

Based on its histological architecture, the muscle spindle recognized in the present specimen was diagnosed as mammalian. It is true that Maeda et al. ${ }^{8)}$ reported the presence of the muscle spindle structure in the jaw-closing muscles of a landlocked masu salmon Oncorhynchus masou. However, the structure was very simple compared with the spindle in the present specimen. In other lower vertebrates, Barker and Cope ${ }^{9)}$ also described single and tandem types of muscle spindle in the frog Rana spp. and Proske ${ }^{10)}$ mentioned the innervation of muscle spindles, which most commonly contained only a single intrafusal fiber, in the lizard Tiliqua nigrolutea. On the other hand, many investigators have described the distribution and structure of mammalian spindles in different portions such as human popliteus, ${ }^{11)}$ the snout muscle of the shrew-mole Urotrichus talpoides, ${ }^{12)}$ and in the extensor digitorum longus muscle of a rat. ${ }^{13)}$ The spindle in the present specimen is quite similar to those mammalian spindles. ${ }^{14)}$ However, we could not exactly determine the species, since, as far as we know, no reports have been published on muscle spindles of marine mammals (particularly whales).

Nature (particularly whale) conservationists have emphasized the serious issues involved for a business to maintain a jetfoil lane in an area of sea that is migrated through or inhabited by whales. On the other hand, transport administrators hesitate to permit regular licensed shipping if the possibility of passenger endangerment exist. Indeed, in the case of the Sado Line Company, utilizing ferry boats and jetfoils, as was reported by Honma ${ }^{7}$ and Honma et al. (in preparation) many cetaceans have been observed and recorded by the crew.

After the fifth accident on 25 November, 1995 (Table 1), resulting in serious damage to the boat and injuries to the passengers, the Hokkaido Press (17 May, 1996) reported that a baleen whale, lacking the posterior half of its body, had washed up the previous day on the rocky beach of Suttsu Town, Shiribeshi Province of southwestern Hokkaido, facing the Sea of Japan. It had appeared to be comparatively fresh, measuring $6.5 \mathrm{~m}$ in length, $3.5 \mathrm{~m}$ in width and $18 \mathrm{t}$ in weight. The abdomen showed a cross-sectional cut by a sharp-edged object. Thereupon, the staff of the Sado Line Company suggested that this whale might have been the one which collided with the jetfoil, resulting in the amputation of its posterior half which then sank to the bottom near the bow hydrofoil that had broken off from the jetfoil (Table 1). However, the photograph of the whale accompanying the press article was identifiable as a gray whale Eschrichtius robustus (Lillejeborg, 1861), a species not recorded off the west coast of Honshu Island for several decades. Although $E$. robustus is the object of whaling only by the natives of Chukchi, East Siberia, Russia, a small population of this species is also found off the coast of Okhotsk Sea, the Maritime Province of Far East Russia, and the Korean Peninsula. ${ }^{15)}$ Strong argument can be made against the above suggestion. Some six months elapsed from the day of collision with the jetfoil to the discovery of the cetacean carcass. Therefore, the remains would be hardly likely to have been "comparatively fresh".

In conclusion, it is clarified that the Sado Line jetfoil has been involved in collisions with apparently large marine mammals and it may become possible to prevent such collisions in the future.

Acknowledgments We wish to express our sincere thanks to the staff of the Sado Line Company for supplying the precious material, and to Dr. H. Kanazawa, Department of Anatomy, Niigata University School of Medicine, for preparing a photograph of fragments embedded in the muscle mass.

\section{References}

1) Y. Honma: Revised records of the large marine animals stranded on the coast of Niigata and Sado Island in the Sea of Japan. Spec. Publ. Sado Mar. Biol. Stat., Niigata Univ., 5, 1-39 (1990).

2) Y. Honma: Records of marine mammals found and stranded on the coast of Niigata District and Sado Island, Sea of Japan. Monog. Assoc. Geol. Collabr. Japan, 43, 155-165 (1994a).

3) Y. Honma, K. Minowa, Y. Nakamura, and A. Aoyagi: Remarkable strandings of Pacific white sided dolphins, Lagenorhynchus obliquidens Gill, 1865, and other cetaceans on the coast of Niigata District, Sea of Japan, during severe winter conditions, 1992-1993. Bull. Biogeogr. Soc, Japan, 48, 81-86 (1993).

4) Y. Honma, Y. Yamazaki, A. Chiba, and S. Oka: Histological observations on some internal organs of the harbor porpoise, Phocoena phocoena, stranded on the Niigata coast, Sea of Japan. Rep. Sado Mar. Biol. Stat., Nitgata Univ., 22, 1-12 (1992).

5) Y. Honma: Histological studies on the ovaries of beaked whales, Mesoplodon stejnegeri, stranded on the coast of Niigata District, Sea of Japan. Rep. Sado Mar. Biol. Stat., Niigata Univ., 24, 1-10 (1994b).

6) Y. Honma and T. Yamada: Further notes on ovarian histology of the Stejneger's beaked whale, Mesoplodon stejnegeri, from a recent stranding on the coast of Niigata District, Sea of Japan. Bull. Natl. Sci. Mus., Tokyo, A, 21, 109-118 (1995).

7) Y. Honma: Sighting records of whales in the Sado Lines (Sado Line Company) navigating across Sado strait-duing the year 1994. Bull. Niigata Pref. Biol. Soc. Educ., 30, 39-43 (1995) (in Japanese).

8) N. Maeda, S. Miyoshi, and H. Toh: First observation of a muscle spindle in fish. Nature, 302, 61-62.

9) D. Barker and M. Cope: Tandem muscle-spindles in the frog. $J$. Anat., 96, 49-57 (1962).

10) U. Proske: The innervation of muscle spindles in the lizard, Tiliqua nigrolutea. J. Anat., 105, 217-230 (1969).

11) H. S. Amonoo-Kuof: Morphology of muscle spindles in the human popliteus muscle. Acta Anat., 124, 48-53 (1989).

12) K. Kubota and T. Masegi: Muscle spindle distribution in snout musculature of the Japanese shrew-mole. Anat. Rec., 172, 703-710 (1972).

13) Y. Takeuchi, K. Asamoto, and Y. Nojyo: Study on the distribution of muscle spindles in the rat extensor digitorum longus muscle. Acta Anat. Nippon., 70, 313-321.

14) Y. Uehara and J. Desaki: A comparative study of muscle spindle. Adv. Neurol. Sci., 25, 403-416 (1981) (in Japanese).

15) A. A. Berzin and V. L. Vladimirov: Recent distribution and abundance of cetaceans in the Sea of Okhotsk. Mar. Biol. (Biol. Morya), 2, 15-23 (1989) (in Russian). 